\title{
An Early Identification of Autism Spectrum Disorder and Intervention/Treatment for Children: Two Case Studies
}

\section{Eruslu E*}

Specialist Mental Health Services \& Psychometric Testing, UK

\begin{abstract}
Autism Spectrum Disorder (ASD) is a developmental disorder, which has greater implications on vulnerable children than adults and it is therefore crucial to identify signs and symptoms at the earliest opportunity to accommodate for the affected child. Targeted treatment methods, such as social skills training, 1-to-1 tuition, speech therapy and Social Stories and Comic Strip Conversation can then be applied early on, which can then lead to substantial improvements at adulthood. Case studies of two male children, aged 4 and 9 were looked into, to identify their special needs. A potential link between genetic factors and ASD was observed, as the children were related to each other (cousins) and showed similar autistic traits. By applying the Autism Diagnostic Interview-Revised (ADI-R), observing and communicating with the children and family members, there were clear indications for ASD. The importance of a multidisciplinary system has been suggested to support the easier and quicker identification of ASD.

Keywords: Autism diagnostic, Intervention, Social skills training, ADI-R, Multidisciplinary system and Ethics
\end{abstract}

\section{Introduction}

Currently approximately $1 \%$ of children and $2 \%$ of adults in the UK have Autism Spectrum Disorder (ASD). ${ }^{1}$ A potential reason for this could be that autism is not easily identified in children, as some of the signs and symptoms could be considered as 'normal' child development, e.g., occasional inattention to important social cues or an emotional outburst. Research indicates that ASD is moderately often misdiagnosed for Attention Deficit Hyperactivity Disorder (ADHD). Kentrou illustrated this, as moderately often ADHD is diagnosed in children rather than the correct ASD, as the symptoms can be very similar and not easy to distinguish early on. ${ }^{2}$ Furthermore, they identified that a multidimensional and multidisciplinary screening procedures is essential to overcome this downside. The consequence is often that the child is than treated for symptoms, which does not cover the whole spectrum. Children are going through an important developmental stage and interact with many other children (who are going through a similar developmental phase) and if ASD is not confirmed, misunderstandings are even further created. The child is then in an environment where her/his special needs are not taken into account, very often misinterpreted by even teachers and bullying by other children takes place. Education and discipline are only partially successful, as it does not only require the need for educating the general public, including children about what ASD is but teaching them the crucial acceptance, tolerance and respect.

Even though, complicated and potentially costly, it is still important to take into account the entire biography of a person, to decide if they have autism. However, this has the advantage that children are naturally quite young and therefore the complete history should not be very long, if identi-
Quick Response Code:

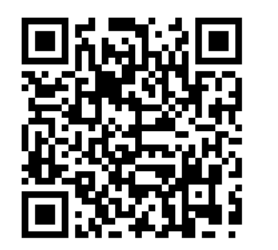

*Corresponding author: Ender Eruslu, Chartered Psychologist, The Quadrus Centre, Woodstock Way, Boldon Business Park, Sunderland, Tyne and Wear, NE35 9PF, UK

Received: 30 October, 2021

Published: 06 December, 2021

Citation: Eruslu E. An Early Identification of Autism Spectrum Disorder and Intervention/ Treatment for Children: Two Case Studies. J Psych Sci Res. 2021;1(5):1-6. DOI: 10.53902/JPSSR.2021.01.000521 
fied early on in the child's life. The early diagnosis cannot only be beneficial for the child in later life but this could also have positive economic implications, as it reduces costs for the state and would put less strain on the health system too.

A psychometric tool named Autism Diagnostic Interview-Revised (ADI-R) was applied to see, if there are any indications for ASD. ${ }^{3}$ This can be applied as a standalone tool but is sometimes also used alongside with the Autism Diagnostic Observation Schedule (ADOS). ADI-R is a sophisticated, comprehensive and standardised interview method, which is primarily directed at the parents of the child but could otherwise involve the caretaker. The ADI-R comprises of four key areas, as follows:

\section{A: Qualitative Abnormalities in Reciprocal Social In-} teraction.

\section{B: Qualitative Abnormalities in Communication.}

C: Restricted, Repetitive, and Stereotyped Patterns of Behaviour.

\section{D: Abnormality of Development Evident at or Before 36 Months.}

However, only the first three components (A, B and C) are taken into account to come to a formal conclusion, if there are indications for ASD.

The updated Diagnostic and Statistical Manual of Mental Disorders (DSM-V) does not make a distinction anymore between different subgroups in autism and has them therefore under the same umbrella 'autism spectrum disorder.' Nevertheless, the ADI-R and the DSM-V still recommends checking for subgroups, such as Asperger's Syndrome or Pervasive Developmental Disorder-Not Otherwise Specified (PDD-NOS).

The parents of the children gave permission for the information to be published as a research article in a journal and were informed that their identities will be kept anonymous to safeguard them. Therefore, the children in Case Study I and II will be addressed as Child A and Child B.

\section{Case Study I}

A male child who was 9 years of age and had shown previous signs of ASD was seen. It was crucial to involve the family as much as possible in the process to gain a better understanding about the signs, symptoms and how his special needs could be addressed successfully. The process involved communicating with the child, observing the child but also communicating with the mother to gain a deeper understanding about his history (duration 6 weeks). Prior to the sessions, medical, psychological and educational reports were provided. The sessions took place remotely using a videoconferencing tool. This was particularly important, because of the pandemic and the social distancing component but also because the children lived further away and could not attend in practice. The remote sessions adhered to the British Psychological Society's (BPS) conduct and practice and the quality of the audio and video were on a very high standard, making the sessions and the outcomes reliable. ${ }^{5}$

Some speech delays and behavioural issues were identified early on by the grandmother of the affected child's life. Permission was gained from the mother of the child to have the grandmother attending the sessions too and this was granted. It is a common occurrence that parents cannot immediately notice behaviour and speech, which deviates slightly from the norm. This was the parents' first child and certain behavioural differences could be misidentified as being mischievous. Observing the recorded videos of the child, one could notice speech problems at a very early stage. A common feature in individuals with autism is the touch sensitivity, which was observable in one case where the child felt visibly uncomfortable on the lap of his uncle and was pushing the hand away from him and showed distress in his facial expression. Rutter states that it is crucial to look into any form of abuse during pregnancy, as it is relevant for ASD and the mother experience psychological and physical abuse from the biological father of the child, which could alter the development. The mother experienced also abuse from her husband prior to the pregnancy. Robert's research indicates the risk of ASD in children, when the mother has been exposed to abuse. ${ }^{6}$ They found that the fear of the partner or the actual sexual, physical and emotional abuse, two years prior to the birth increased the risk for the child for having ASD. Therefore, the study suggests environmental factors to be, at least a contributing factor for ASD and this has to be considered for any intervention methods. The potential genetic factors were confirmed, as Child A is the cousin of Child $B$ (which will be discussed below) and therefore a correlation could be established.

By looking into the signs and symptoms regarding Asperger's Syndrome (AS), this could be excluded, as Child A has language delays/problems and there are generally no speech delays in AS and they are often very articulate. However, looking into the PDD-NOS and its symptoms, it was noticed, from the observation and communication with Child A that this matches his traits/symptoms almost entirely. Even though, the child's speech impairment was audible, there was still sophistication in his verbal expression but he also 
kept sentences very brief. This could be further improved with more effective practice, e.g., by a Special Needs Teacher and/or Speech Therapist and an environment, which promotes growth. He was more open and fluent, whilst talking about his interests, e.g., Super Mario (videogame). Therefore, videogames could be combined with social scenarios, which could help him cope with social cues. It is crucial that autistic children are given sufficient time to express themselves, without the fear of being misunderstood, judged or being under pressure of time. Here, Carl Ransom Rogers' person-centred approach could be applied as its core principles are important, i.e., Genuineness (not putting a false façade but being authentic), Empathy (understanding the predicament of the child and their special needs) and Unconditional Positive Regard (not judging the child but accepting them as who they are and seeing their potential and not their shortcomings). ${ }^{7}$

An often-applied test for potential autistic traits is the usage of figurative language, as children with ASD are usually not able to distinguish the different meanings it can have. When Child A was asked about what the following sentence means: 'The early bird catches the worm'. He replied: 'The bird wakes up and catches a worm'. This feature is also specifically observed in PDD-NOS (having difficulty to understand that statements could have wider or multiple meanings rather than being taken literally or being absolute). ${ }^{8}$ At another time, we praised him for his creative and engineering abilities, as he often constructs sophisticated buildings out of cardboard boxes, e.g., houses/rooms. His aunt mentioned in a nice and humorous manner: 'Do not forget to build me a house, when you become an architect!' His mother reported back, that he took this statement literally and built her sister a house out of cardboards, so he could also come and visit her. The rationale behind this is that his aunt has a smaller house, which makes it difficult to accommodate an additional person but the child took the cardboard building as a literal representation of an additional room or space and therefore he could come and visit his aunt now. Child A has issues throwing household waste away, e.g., cardboards or plastic bottles. He often feels sad, when normal household trash is thrown out. The potential reasoning, from his point of view is that he can re-use or recycle them and he has the ability to create buildings/houses and rooms, with meticulous details. It is often the case with individuals who have ASD, to have special gifts and Child A is very talented in drawing/painting. He has the ability to paint pictures of a very high standard and prefers to draw nature, such as landscapes. The final result appears to be much above his age group and could potentially appear in an arts gallery.
Executive dysfunction is often associated with ASD and comprises, working memory, planning and mental flexibility. ${ }^{9}$ Whilst building a rapport and communicating with the mother and grandmother of Child A, certain executive dysfunctions were discovered, relating to his memory and organisation. This became visible, when he was asked at the beginning of the session, what he has done today and if he had played with his favourite toys. He replied a couple of times with the sentence: 'I don't know!', which appeared to indicate a memory impairment. The mother of Child A confirmed a potential dysfunction, as he cannot plan ahead and is very disordered, e.g., cleaning his room and keeping his belongings in order to keep his room tidy.

During a conversation about Child A, the mother became visibly distressed and was crying, as the demands of a child with autism are immense. She narrated that the behaviour exhausted her energies and the countless tasks where overwhelming, e.g. helping with homework. She lacked the essential support needed to help the affected child. Child $A$ and the mother stated that he was bullied, harassed and did not only experience psychological and emotional abuse but was also physically assaulted, by fellow pupils at his previous mainstream school and that his special needs were either not accommodated for or could not be understood. He also stated that when he put his hand up in class to answer a question or to make a statement, he was always ignored by the teacher and because he felt not attended to it resulted in emotional outbursts. His new online school stated that his behaviour has improved and his grades are generally above the national average. A school environment is filled with many environmental cues, e.g., noises. An autistic child can easily become overwhelmed with this and the countless social scenarios, where they might not have a suitable reaction to it. Child A has sensory issues and this includes loud noises and lighting, which can cause great distress and could lead to destructive behaviour. The mother stated that she has limited knowledge but has to help her son with many subjects, which was also echoed by her son, as he found the homework difficult to cope. It is recommended to have 1-to-1 tuition with a qualified teacher, who specialises specifically in ASD, to cover the traits and to help Child A's development. The University of Southampton conducted research and the result showed that those autistic children who received intensive teaching sessions had higher IQ scores, more advanced language skills and better daily living skills than autistic children receiving standard educational delivery. ${ }^{10,11}$ A gait deviation was observed in Child A, as his walk is compromised by a weak control of his feet and legs. He is also very flexible with his fingers and toes and this could potentially lead to painful joints 
and might require to be checked for Joint Hypermobility Syndrome or Ehlers-Danlos syndromes. ${ }^{12}$ From the observation and the mother's narration, Child A tip-toes occasionally, which can be associated with ASD. Research suggests that this could potentially lead to bone diseases, such as scoliosis (curvature of the spine). ${ }^{13-15}$ It is crucial for this to be seen by a specialist physician (Neurologist and/or an Orthopaedic), so potential negative effects on the physical developed can be intervened, e.g., adjusted/special shoes.

Individuals with ASD commonly experience anxiety, which was the case with Child A too. ${ }^{16}$ Even though the mother attempts to socialise Child A with others, he has no friends. The mother claims that he often hides from others, if a new individual comes to their house but also sometimes when other family members from different households arrive. He does not like his daily routine to be disturbed. Autistic individuals have their individual rituals and routines and if this deviates, they can become very agitated and aggressive ${ }^{17}$ Child A might fear the unknown when certain rituals and routines are broken, as this gives him the essential certainty, he needs to control the anxiety. He stated that other children annoy him and this might be paired with his previous experience with bullying and being hit by other children. Autistic people are often touch sensitive and have therefore sensory issues too..$^{18}$ Child A stated, that he does not like to be touched, as it feels tight, uncomfortable, suffocating or even hurts him. The mother stated that she tries to accommodate for his sensory needs with different coloured lighting, which simulates sensory stimulation rooms and can help an autistic child to relax.

As covered previously, Child A illustrates indicates atypical body movements but also specific hand and finger mannerism. This is also called 'stimming', which are reoccurring, unusual movement and/or noises. ${ }^{19}$ Paradoxically, this short-term self-stimulatory action, could have relaxing effects or easing the potential emotional and physical pain on the child. Child A often find strings and wraps this so tightly around his index finger, that the mother becomes anxious about his well-being, as it cuts off the blood supply to the extremity. As stimming serves a sensory pleasure for Child A, a harmless alternative was suggested, such as an elastic rubber band. The mother's feedback on this was very positive, as it was introduced to the child and he appears to have accepted this, as a substitute for the string. Another suggestion for the urge for sensory input was displayed in Child A's requirement to bite his finger but more frequently the finger of his mother, albeit in a sensible manner. This biting input is often observed by autistic children, as a form of sensory feedback..$^{20}$ Child A stated that he likes the sensation of biting, as it gives him satisfaction.

\section{Case Study II}

Many features, which were exhibited by Child A, were also present in Child B, because of the relatedness and therefore they were not repeated or kept brief, to focus on novel features. The procedure of conducting the sessions and the ADI-R was identical and obeyed to the BPS's standards. Child A was 4-year-old and was seen for a period of 5 weeks. As the child was still very young, there were no existing medical, psychological or school reports available but with permission video recordings of his behaviour were received and seen. The ADI-R was done with the mother of the child but as in the previous case, permission was given to have her sister and the grandmother of the child present to gain additional input. The results showed again that Child B, was very likely autistic. Noticeable differences were that the mother had not experienced any kind of abuse; was married and she had three additional children ( 6 and 8 years of age and an infant of 10 months). Especially, the older siblings might have had a positive influence on his development, as Child B tended to smile much more frequently and was generally happier than Child A. According to Vygotskty, 'knowledgeable others' such as older siblings act usually as role models, where an infant/ child learns how to behave and progress. ${ }^{21}$ The direct social input and a bigger immediate family might have had a positive impact on Child B's development. It is a common feature in parents that they might perceive the child's misbehaviour/ condition as only temporary, as it was stated by the mother of Child B. This might be due to the lack of knowledge about ASD or linked to the fact that both parents saw the symptoms individually and isolated from another and realised later on that many autistic traits were observable.

As covered in Case Study I, ASD can be misdiagnosed for ADHD and one indication how this could occur was observed in a video recording of Child B, were he appeared to not pay attention. Child B was running around the room and playing and the 10 months old sister was sitting next to the sofa and had the TV's remote control in her hand. Child B grabbed unintentionally but may be forcefully the remote control out of the infant's hand and as a result she started crying. At the very same time the mother asked: 'What happened to your sister?' and as a result Child B became visibly distressed. It appears that he did not understand what had occurred, as he could not make the connection between his acts and the reaction of his sister and the mother becoming upset. Autistic children are sometimes noise sensitive and they might not 
be able to relate to others but this might be perceived, as disregarding them on purpose, if ASD is not identified. ${ }^{22,23}$

Child B keeps speech generally brief and sometimes cannot be understood by others but also by his own family. This makes him agitated, as he struggles to put his message across. As with Child A, there are noticeable speech issues with Child B, but there was still sophistication in his expression audible, which could be further advanced with a speech therapist. Child B is an astute and energetic young boy, with his personal interest and he often likes his own company. He enjoys watching television or plays with his favourite toys, such as Super Mario and Yoshi (a dinosaur). Social skills training could be combined with operant conditioning, to teach Child B social norms and cues, such as recognising them and how to reply to them effectively by rewarding the child..$^{24}$ It is extremely difficult for a child with ASD to recognise facial expressions, gestures and other bodily behaviour and the mother of Child B confirmed that she has great difficulties gaining his attention, as he appears absent. A further indication that he might not be able to recognise facial expressions is that he often avoids eye contact.

The mother stated that the nursery Child B enrolled on does not attend to his physical and special needs and might therefore not have the resources to deal with it. The mother stated that Child B cannot count to 10 and he cannot recall the alphabet too, which was confirmed by the nursery but he should at this age be capable of doing so. As in the previous case, Child B would benefit from 1-to-1 tuition, as he is even younger than Child A and the research by the University of Southampton found that intervention at an earlier age increases the likelihood for success. She stated that Child B became very thin, as she did not realise that he did not receive any food for days from the nursery. In recent times, he became fixated on bread, as he even wakes up in the night and cannot go to sleep without eating bread. The sensory issues are similar to Child B, as he dislikes loud noises, lights and does not like his routine/rituals being interrupted or it results in an emotional outburst, which is difficult to control. He often feels very cold when it is really hot and vice versa. Another common feature in autism is becoming agitated and being impatient in situations, where it requires time, e.g., waiting in the queue causes great distress for Child B. The mother gave examples for stereotypical utterances, which indicates delayed echolalia. The child asked: 'Can I go out?' and immediately states: 'Say yes!'. Child B narrated that he dislikes being touched, especially his toes, as it hurts him. His mother told that he likes to smell others, object and chews and licks objects too. According to the mother, Child B dis- played stimming behaviour, such as flapping hands, spinning, running around in circles, hard blinking, pacing, repeating words, jumping and chewing. The chewing element could be due to the autistic child requiring sensory feedback. ${ }^{25}$

Child B's walking is slightly different to Child A, as he walks on inverted toes and this might lead again to orthopaedic issues and should be seen by a specialist medical professional to see if it necessitates correction/adjustments. As Child A is also very flexible with his fingers and toes, this might influence the joints negatively at later time and should be checked for Joint Hypermobility Syndrome or Ehlers-Danlos Syndrome.

\section{Discussion}

It is important to apply a holistic approach to intervention, diagnostic and treatment. As it is the case very often but not always, a multidisciplinary team (for instance, psychologists, psychiatrists, educators, speech therapists, parents and/or caretakers) should be involved in the diagnosis of ASD, as the signs and symptoms could be misinterpreted easily. Taking into account as much information as possible at the earliest stage of the affected person's life does not only ensure that the diagnosis is more precise, but the child has a more successful social, cognitive and physical development.

Stimming could be an escape from an overwhelming situation for the affected child and therefore needs to be addressed, rather than eliminated. It is important to substitute the potential harmful stimming to a gentler alternative, such as a child friendly rubber band, rather than a non-elastic string. This could also include motives, which combines the interest of the child, so the choice is made easier and the sensory satisfaction is still achieved. A similar approach could be applied to the urge of biting and the preferred finger could be replaced with another item, such as a soft rubber toy to be chewed/bitten or the index finger could have a rubber protective cover.

To accommodate Child A's and Child B's sensory issues, their personal environment could resemble a sensory stimulation room, as much as possible, e.g., different coloured lights (potentially dimmed) and lava lamps. It can create a relaxing and non-threatening atmosphere and has a calming effect on them. However, if this is not feasible, the children could join a sensory stimulation room regularly, which is available in their near environment.

Child A and Child B need Social Stories and Comic Strip Conversations to help them make sense of the social world and interact effectively with others. Social Stories are brief 
descriptions of specific social situations and helps the autistic child what to expect and how to appropriately react to it. ${ }^{26}$ As the name suggests, Comic Strips Conversations use particular drawings of social situations, which could be further simplified by applying humour to them, so the child can relate to it. ${ }^{27}$ The importance lies in the holistic approach and accommodating for the child and therefore it is recommended to take into account the ethnicity and/or religion in the particular stories and conversations.

Equine Therapy is an additional recommendation, as it can help children with ASD to interact with non-humans and this might ease the interaction. Human communication can be a very complicated process, as it requires an understanding of multiple cues, such as different facial expressions, tone of voice, metaphors, figurative language and gestures. Research suggests that equine therapy has positive effects on social communication and improves behavioural skills too in autistic individuals. An animal such as a horse excludes the complicated social cues in humans and does not overwhelm the autistic child and they can interact in simpler form. ${ }^{28}$

\section{Acknowledgments}

None.

\section{Funding}

None.

\section{Conflicts of Interest}

Author declares that there is no conflict of interest.

\section{References}

1. NHS Digital. Autism Waiting Time Statistics - Quarter 1 to quarter 4 2019-20 and Quarter 1. 2020.

2. Kentrou V, De Veld, Mataw JKK, et al. Delayed autism spectrum disorder recognition in children and adolescents previously diagnosed with attention-deficit/hyperactivity disorder. Autism. 2019;23(4):10651072.

3. Lord C, Rutter M, Le Couteur A. Autism Diagnostic Interview-Revised: a revised version of a diagnostic interview for caregivers of individuals with possible pervasive developmental disorders. J Autism Dev Disord. 1994;24(5):659-685.

4. Arlington VA. American Psychiatric Association. Diagnostic and Statistical Manual of Mental Disorders. $5^{\text {th }}$ ed. 2013.

5. The British Psychological Society. Guidelines on Psychological Assessment Undertaken Remotely. 2020.

6. Roberts AL, Lyall K, Rich-Edwards JW, et al. Maternal exposure to intimate partner abuse before birth is associated with autism spectrum disorder in offspring. Autism. 2016;20(1):26-36.

7. Rogers CR. Client centered therapy: Its current practice, implications and theory. London: Constable. 1951.
8. Ivey LM, Heflin J, Alberto P. The use of social stories to promote independent behaviors in novel events for children with PDD-NOS. Focus on Autism and Other Developmental Disabilities. 2004;19(3):164-176.

9. Hill EL. Executive dysfunction in autism. Trends Cogn Sci. 2004;8(1):26-32.

10. University of Southampton. Research reveals early intervention provides key to increased IQ in children with autism. 2007.

11. Symes MD, Remington B, Brown T, et al. Early intensive behavioral intervention for children with autism: therapists' perspectives on achieving procedural fidelity. Res Dev Disabil. 2006;27(1):30-42.

12. Baeza Velasco C, Cohen D, Hamonet C, et al. Autism, Joint Hypermobility-Related Disorders and Pain. Frontiers in Psychiatry. 2018.

13. Calhoun M, Longworth M, Chester LV. Gait patterns in children with autism. Clinical Biomechanics. 2011;8(1):200-206.

14. Hediger LM, England LJ, Molloy CA, et al. Reduced bone cortical thickness in boys with autism or autism spectrum disorder. Journal of $\mathrm{Au}$ tism and Developmental Disorders. 2008;38(5):848-856.

15. Barrow WJ, Jaworski M, Accardo PJ. Persistent toe walking in autism.J Child Neurol. 2011;26(5):619-621.

16. Vasa RA, Mazurek MO. An update on anxiety in youth with autism spectrum disorders. Curr Opin Psychiatry. 2015;28(2):83-90.

17. Howlin P. Practitioner review: psychological and educational treatments for autism. J Child Psychol Psychiatry. 1998;39(3):307-322.

18. Riquelme I, Hatem SM, Montoya P. Abnormal Pressure Pain, Touch Sensitivity, Proprioception, and Manual Dexterity in Children with Autism Spectrum Disorders. Neural Plast. 2016;2016:1723401.

19. Masiran R. Stimming behaviour in a 4-year-old girl with autism spectrum disorder. BMJ Case Rep. 2018;2018:bcr2017223671.

20. Devine DP. Self-injurious behaviour in autistic children: a neuro-developmental theory of social and environmental isolation. Psychopharmacology (Berl). 2014;231(6):979-997.

21. Vygotsky LS. Mind in society: The development of higher mental processes. E. Rice, Trans, editors. 1978.

22. Kanakri SM, Shepley M, Varni JW, et al. Noise and autism spectrum disorder in children: An exploratory survey. Res Dev Disabil. 2017;63:8594

23. Byom LJ, Mutlu B. Theory of mind: mechanisms, methods, and new directions. Front Hum Neurosci. 2013;7:413.

24. Neimy H, Pelaez M, Carrow J, et al. Infants at risk of autism and developmental disorders: Establishing early social skills. Behavioral Development Bulletin. 2017;22(1):6-22.

25. McCarty MJ, Brumback AC. Rethinking Stereotypies in Autism. Semin Pediatr Neurol. 2021;38:100897.

26. Hutchins LT, Prelock AP. Parents' Perceptions of Their Children's Social Behavior: The Social Validity of Social Stories ${ }^{\mathrm{TM}}$ and Comic Strip Conversations. Journal of Positive Behavior Interventions. 2012;15(3):156-168.

27. Hutchins TL, Prelock PA. Using social stories and comic strip conversations to promote socially valid outcomes for children with autism. Semin Speech Lang. 2006;27(1):47-59.

28. Srinivasan SM, Cavagnino DT, Bhat AN. Effects of Equine Therapy on Individuals with Autism Spectrum Disorder: A Systematic Review. Rev J Autism Dev Disord. 2018;5(2):156-175. 